\title{
Prune belly syndrome - A case report
}

D.Rupshikha ${ }^{1}$, M.J. Phukon², G.R. Kusre ${ }^{3}$, N. Satyanarayana ${ }^{4}$, P. Sunitha ${ }^{5}$

${ }^{1,2}$ Associate Prof, Dept. of Anatomy, Prathima Institute of Medical Sciences, ${ }^{3}$ Assoc. Prof, Dept of Anatomy, Assam Medical College. ${ }^{4}$ Assistant Professor in Anatomy, ${ }^{5}$ Assistant Professor in Physiology, College of Medical Sciences, Bharatpur, Nepal.

\begin{abstract}
Prune Belly Syndrome (PBS) is a rare congenital anomaly. A male baby was received from the Department of Paediatrics, Assam Medical College hospital which died on the second day of birth. It was a diagnosed case of Prune Belly Syndrome (PBS) due to its flabby abdominal wall ballooning out in flanks and skin creases radiating laterally and downwards from the umbilicus - "Prune" like appearance. It was observed that the baby had congenital absence of abdominal muscles and undescended testis. On dissection, associated defects of urinary tract and gastro intestinal tract, persistent cloaca and preductalcoarctation of aorta were noted. The aetiology of this case owes for an overall mesenchymal defect.
\end{abstract}

Keywords: Abdominal muscle deficiency, urogenital defects, persistant cloaca, renal dysplasia, coarctation of aorta.

\section{Introduction}

Other names for Prune Belly Syndrome (PBS)- EagleBarret syndrome, Triad, Osler- Parker Syndrome, Abdominal muscle deficiency syndrome, Mesenchymal dysplasia syndrome. Partial or complete absence of abdominal musculature is called Prune Belly Syndrome (PBS). It is associated with malformation of Urinary tract and bladder, or genitourinary abnormalities. These cause accumulation of fluid that distends the abdomen resulting in atrophy of the abdominal muscles. The wrinkled appearance of the dystrophic abdominal wall is responsible for the Prune like appearance of the abdomen. ${ }^{1}$

Correspondence: D. Rupshikha

E-mail: roopsikha@yahoo.com

\section{Case report}

A male baby was received from the Department of Paediatrics, Assam Medical College hospital. The present case was a vaginally delivered, full-term male baby which was diagnosed to be a case of Prune Belly Syndrome because of its flabby abdominal wall ballooning out in the flanks and skin creases radiating laterally and downwards from the umbilicus . It died on the $2^{\text {nd }}$ day of birth in the baby room of the paediatrics department. The mother has one living issue and gave a history of losing her second baby few hours after birth due to certain unknown cause. No drug history was given. The chromosomal study could not be done. 
D.Rupshikha, Prune belly syndrome - A case report

Anatomical observations - The baby had congenital absence of abdominal muscles because of which the overlying skin had “dried plum” appearance (Fig. 1). On dissection, the followings were observed (Fig. 2,3,4): Abdominal wall consists of only skin, fat and fibrous tissue on the peritoneum. Moreover distended intestines , hydronephrotic right kidney, dilated and tortuous right ureter, absent left kidney and left ureter, opening of the sigmoid colon into the bladder , anorectal agenesis , persistent cloaca, undescended testis were noted. The stomach had atretic cardiac end and was very much enlarged with fluid.

In the cardiovascular system, preductal coarctation of aorta was noted (Fig. 5). The other systems were found to be normal.

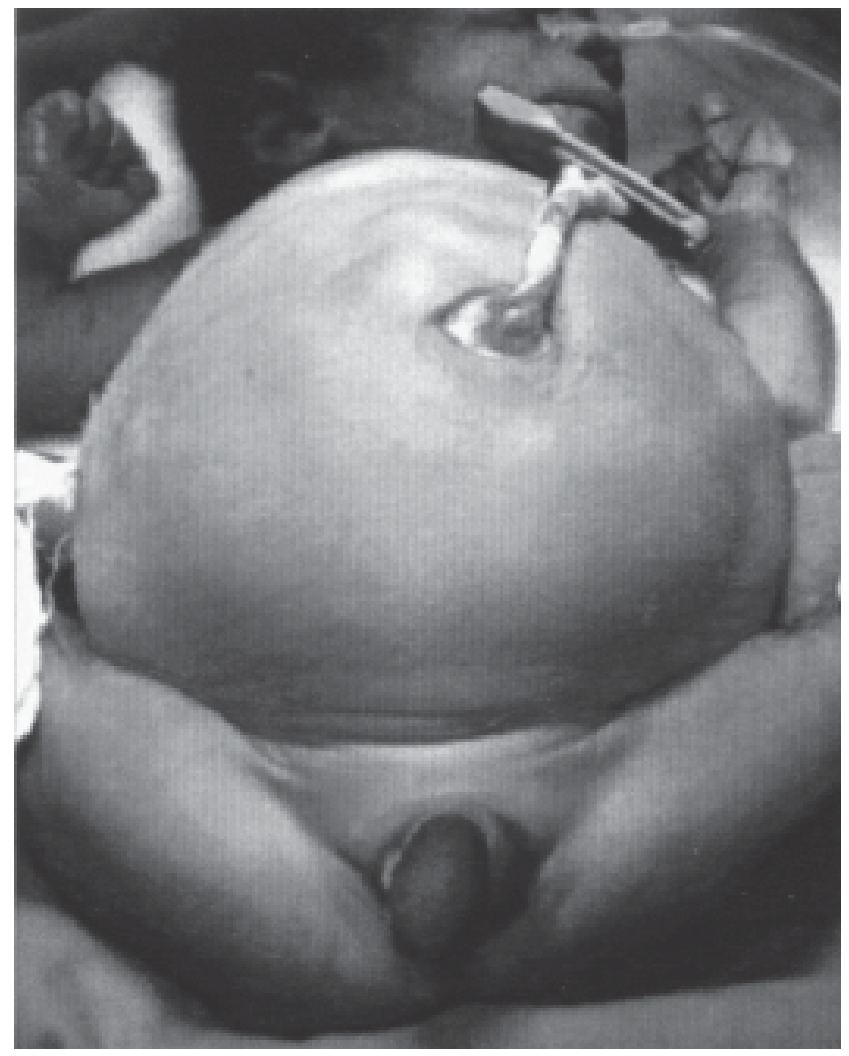

Fig. 1: shows i) Flabby abdominal wall, skin creases radiating out from umbilicus "Prune" like appreance, ii) undescended testes

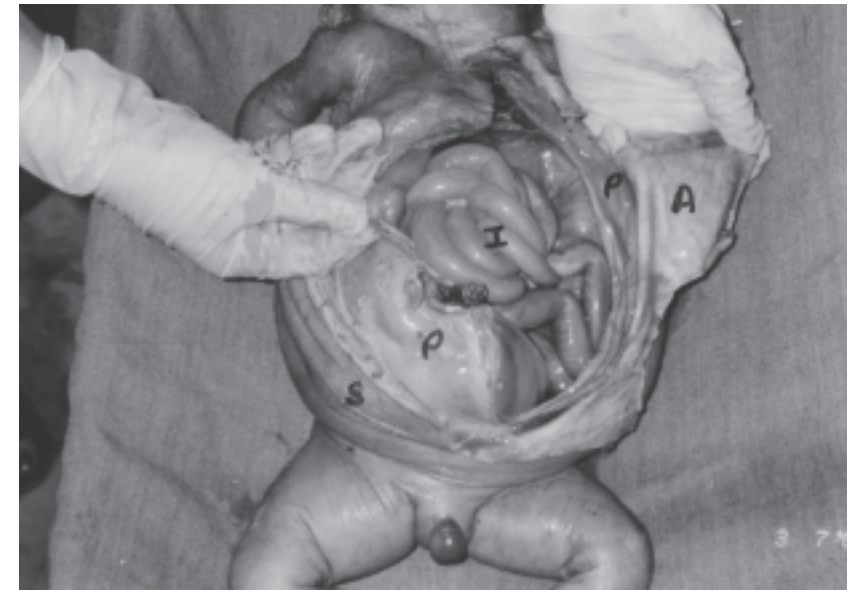

Fig. 2: showing absent anterior abdominal wall.

A = Absent abdominal wall, $\mathrm{I}=$ Intestines,

$\mathbf{P}=$ Peritoneum, $\mathrm{S}=$ Skin.

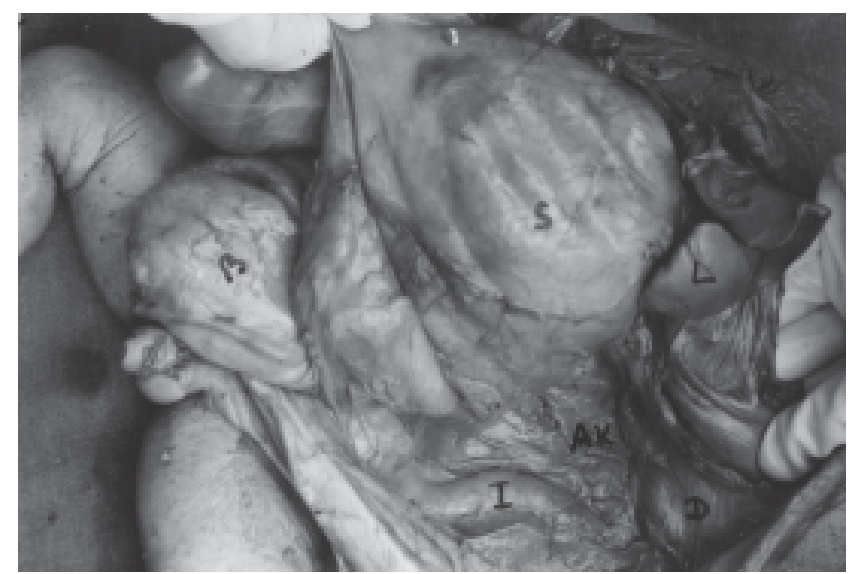

Fig. 3: showing absence of left kidney.

I= Intestine, AK= Absent kidney(Left) , L= Liver, $D=$ Diaphram , S=Stomach

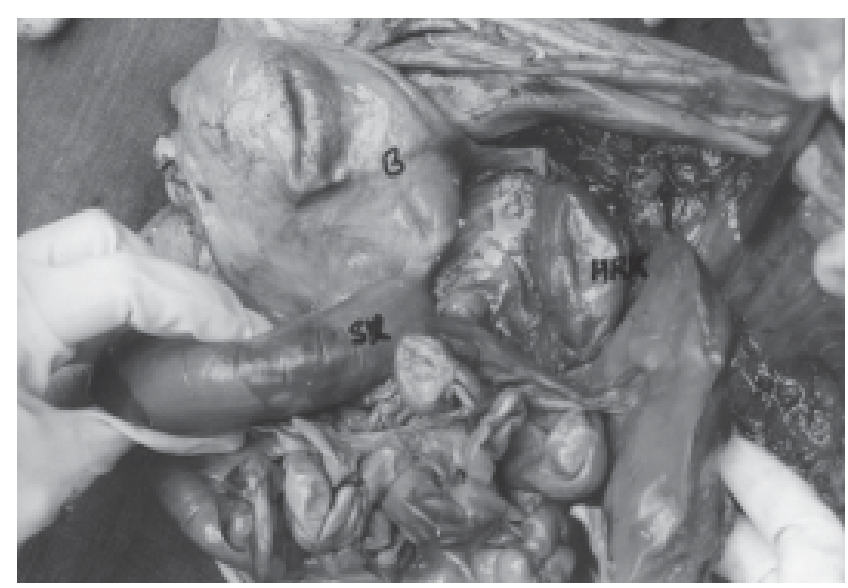

Fig. 4: showing Hydronephrotic right kidney.

HRK= Hydronephrotic right kidney, $B=$ Bladder, SK $=$ Sigmoid colon 


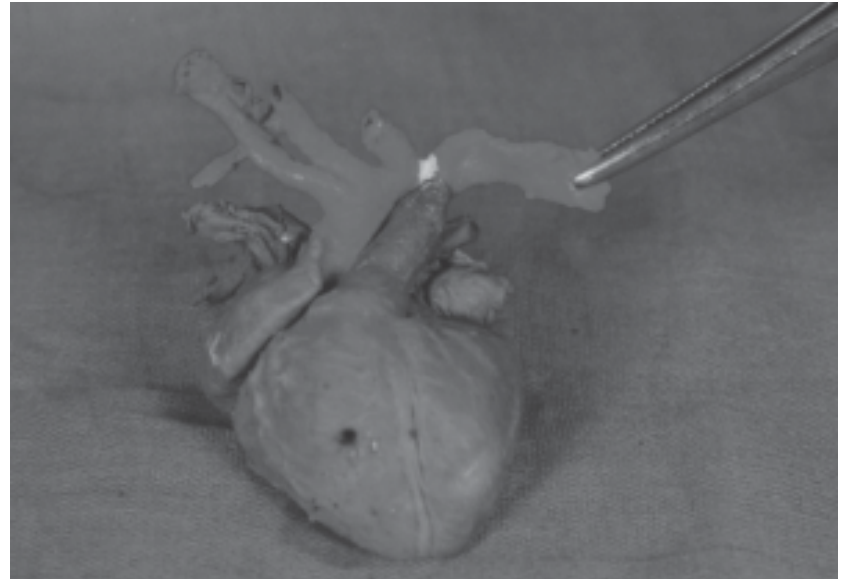

Fig. 5: showing Co- arctation of Aorta(COA)

\section{Discussion}

This anomaly was first described by Frolichs in $1839 .^{2}$ Parker in 1895 presented a case with deficient abdominal wall musculature and dilatation of the urinary tract. ${ }^{3,4}$ The term Prune Belly was first coined by Oslar in 1901, as the skin of the patient had dried plum appearance with skin creases. ${ }^{4}$

In 1950, Eagle Barret described a syndrome involving congenital deficiency of the abdominal muscles with associated genitourinary abnormalities called the “Triad” or Eagle Barret Syndrome. ${ }^{4}$ History says that infants born with a full blown syndrome have had a poor prognosis for long term survival. ${ }^{2}$

Prune Belly Syndrome is a rare congenital disease. Incidence: 1: 35,000 to 1:50,000 live births. Twins, blacks and children born to younger mother appear to be at higher risk in epidemiological studies. ${ }^{2,5}$

The defect is almost exclusively seen in males. A fully developed syndrome is seen only in this sex. ${ }^{3} \mathrm{An}$ incomplete one, called the female syndrome is rare, accounting less than 3\%. Up to1980, only 23 female cases were reported. The defect involves abdominal wall, bladder, and upper urinary tract. "PseudoPrune
Belly syndrome" term is suggested to the incomplete, or the female syndrome. ${ }^{6,7}$ This syndrome is reported to occur in all races . ${ }^{2}$ Associated defects: Clinically significant non-urological features are noted in 7.3\% of cases, among which cardiac $10 \%$, pulmonary $55 \%$, gastrointestinal 31\% , and orthopedics being 40-63\% .$^{8,9}$ Most of the cases of PBS are sporadic with normal karyotype, though few familial cases and twins is also reported. ${ }^{10,11}$ The genetic basis has been explored but no clear inheritance pattern has emerged.The observation of $100 \%$ discordance among all twins in whom monozygosity has been proven, goes against a genetic aetiology. ${ }^{12}$ However, the reported association with Turner's syndrome, monosomy 16, Trisomy 13 and Trisomy 15 confound identification of a simple gene locus. ${ }^{10,13,14,15}$ According to Felix et al (1997), the pattern of inheritance may be a two steps autosomal dominant mutation with sex limited expression that partially mimics X-linkage. This theory accounts for the predominance of male subject and occasional familial occurrence. ${ }^{4,10,11}$

Another theory implicates disordered mesodermmal development during early embryogenesis. Alocalized abnormality of the mesoderm iniated at $23^{\text {rd }}$ day of development before lateralization or somite formation or at the time of initial formation of the primitive streak , would account for the abnormal muscle deficiency (paraxial), renal abnormalities ( intermediate), and abnormalities in the musculature of the ureters, bladder and gubernaculums i.e. lateral plate mesoderm . ${ }^{16,17}$ The lack of prostatic epithelial differentiation further supports a primary mesenchymal developmental defect. $^{9}$

Several investigators have suggested that prostate dysgenesis and fetal ascites are key factorsin causation 
D.Rupshikha, Prune belly syndrome - A case report

of Prune Belly Syndrome (PBS), with foetal ascites producing the abdominal wall defects. ${ }^{18,19.20}$

The muscle involvement in Prune Belly Syndrome (PBS) varies from partial hypoplasia to complete absence of abdominal musculature. The involvement may be generalized, more hypoplastic through the lower abdominal musculature, or limited to one side of the abdomen. The upper rectus abdominis are better developed than the lower. In some cases lower medial aspects of abdominal wall consist of only skin, fat and condensed fibrous tissue on the peritoneum. The descending order of frequency of deficient muscles is: transverses abdominis and rectus abdominis below the umbilicus; internal oblique,external oblique and rectus abdominis above the umbilicus. ${ }^{4}$

This syndrome presents with wide range of severity. The babies may be born of entirely normal pregnancies, or associated with oligohydromnios.

Prenatal diagnosis is rare. They are usually diagnosed during the neonatal period. Successful prenatal diagnosis of Prune Belly Syndrome (PBS) by ultrasonography has been made as early as 14 week of gestation. ${ }^{21}$ Occasionally the defects if seen in adults, they present with hypertension secondary to renal disease. ${ }^{3}$ Prognosis of the patient depends on the severity of renal dysplasia. Respiratory compromise (eg. pneumonia, atelectasis,etc)secondary to abdominal muscle deficiency is seen. In these cases, a maternal history of oligohydramnios is usully noted. ${ }^{2}$

With advances in imaging and urodynamics,paediatric urologists take a more conservative stand. Even the less affected children require a long term follow up care. If required, operation is recommended soon after the $1^{\text {st }}$ birthday of the baby. ${ }^{22}$

\section{Conclusion}

The present case is a complete variety of Prune Belly Syndrome (PBS) due to complete absence of abdominal muscles and genito-urinary defects associated with cardiac and gastro-intestinal anomalies. It died on the second day of birth due to cardiorespiratory failure. Children with Prune Belly Syndrome (PBS) should be evaluated and treated at institutions equipped with current imaginary facilities and by urologists who have complete knowledge of the wide spectrum of this disorder.

Besides, the pregnant ladies should have regular antenatal check up and health education regarding intake of nutritious food, folic acid, required vitamins and minerals. Medicines should be avoided, unless a doctor advices. Genetic counseling of parents is important, especially those with a history of abortion, perinatal death, or with a family history of genetic diseases.

\section{References}

1. T.W.Saddler. Langman's Medical Embryology. In:Muscular system.11th ed. Philadelphia Lippincott Williams \& Wilkins, 2009:152.

2. A.E. Smith, R.John. Campbell Urology-volm. 3. $8^{\text {th }}$ edn Saunders;2002; 2117- 24.

3. Y.I.P. Felix, M.Richard. Pediac Urology $3^{\text {rd }}$ ed, Butterworth Heinemann; 1997, 618-20 .

4. R.W. Parker. Absence of abdominal muscles in an infant Lancet 1835; 1:1252.

5. P.Garlinger, J.oppot. Prune belly syndrome - possible genetic implications. Birth Defects1974;10:173. 
Journal of College of Medical Sciences-Nepal,2011,Vol-7,No-3

6. I.A. Arronson, BJ cremein. Prune belly syndrome in young females. Uro, Radiol 1980,150 -5.

7. R .Rabinowitz, J.F. Schillinger. Prune belly syndrome in the female subject. J. Urol 1977; 118;454-6.

8. D.F.Geary, L.B.MacLusky, B.M.Churchill. A broaderspectrm of abnormalities in the Prune Belly Syndrome. J . Uro 1986; 135, 324.

9. K.A. Burbige, J. Amodio, W.E. Berdon, T.W.Hensle. Prune belly syndrome -35 yrs of experience . J Urol 1987; 137; 86-90.

10. A.A. Adenoyokunna , J.B. Familusi. Prune belly syndrome in two siblings and a first cousin . Am J Dis Child 1982; 136 : 23.

11. D.S Peterson, L.Fish, A.S. Cass. Twins with congenital deficiency of abdominal musculature . J Urol 1972;107; $670-3$.

12. E.J. Ives . The abdominal muscles deficiency triad syndrome : Experience with ten cases. Birth Defects $1974 ; \mathbf{1 0}: 127$.

13. L.M. Harley, W.H. Rather. Prune belly syndrome. Jurol 1972; 108: 174.

14. M. Frydman, R.E. Magenis, T.K. Mohandas. Chromosome abnormalities in infants with prune belly anomaly, Association with Trisomy 18. Am J Med Genet 1983 ; 15: 145

15. H. Beckman, H. Reher, R. Rauskolb. Letter to the editor Prune belly sequence associated with trisoimy 13. Am J Med Genet 1984; 19:603.

16. D.W. Smith. Recognizable patterens of Human Malformation, Philadelphia, WB Saunders 1970;5.

17. A. Edwin, R. John. Campbell's urology vol III, $8^{\text {th }}$ Edn ; Saunders ;2002; 2117- 24

18. I.W. Movie, B.J. Monie. Prune belly syndrome \& fetal ascities. Teratology1979; 7:19.

19. P. Moerman, J.P. Fryns, P. Goddeeris, J.M. Lauweryns. Pathogenesis of the Prune Belly Syndrome, A functional urethral obstruction caused by prostatic hypoplasia . Pediatrics 1984 ; 73:470.

20. D.P. Deklerk, W.W. Scott. Prostatic maldevelopment in the Prune Belly Syndrome, a defect in prostatic stromal epithelial interaction . J. Urol 1978; 120, 341-4.

21. T. Shimizu, Y. Ihara, W. Yomuro . Antenatal diagnosis of Prune Belly Syndrome . Arch GyneccolObstet 1992; 251:211

22. J.R. Schultz, W.M. Klykylo, J. Wacksman. Timing of elective hypospadiasrepaire in children . Paediatrics 1983; 71,349 . 